\title{
Game of Skill or Game of Luck? Motivations for Gambling
}

\author{
Valeria De Bonis ${ }^{1} \&$ Alessandro Gandolfo ${ }^{2}$ \\ ${ }^{1}$ Department of Law, Philosophy and Economic Studies (DiGEF), La Sapienza University, Rome, Italy \\ ${ }^{2}$ Department of Economics and Management (DEM), University of Pisa, Pisa, Italy \\ Correspondence: Valeria De Bonis, Department of Law, Philosophy and Economic Studies (DiGEF), La Sapienza \\ University, piazzale Aldo Moro 5, 00185 Rome, Italy. Tel: 39-06-4991-0727. E-mail: \\ valeria.debonis@uniroma1.it
}

Received: March 24, 2015 Accepted: April 10, 2015 Online Published: May 31, 2015

doi:10.5539/ijms.v7n3p1 URL: http://dx.doi.org/10.5539/ijms.v7n3p1

\begin{abstract}
The paper analyses the differences in gambling motivations of skill and luck gamblers based on the answers to a questionnaire distributed to students from the University of Pisa (Italy). We find that the probability of playing skill rather than luck games is positively correlated to being a male, to the socialization motive and to having a planning attitude and an interest in socializing. Instead, findings show that it is negatively correlated to the money motive, the perceived risk of losing social esteem, and age. Results are then applied to marketing strategies and public policies, with particular attention to the online environment.
\end{abstract}

Keywords: motivational aspects of gambling, online gambling, skill and luck games, marketing, public policies in the gambling sector

\section{Introduction}

\subsection{The Growing Interest in the Field of Gambling}

The gambling industry has undergone a relevant expansion in recent years, reaching a net worth of over $\$ 125$ billion in 2013 worldwide; expected growth for 2013-15 is, for instance, 3-5\% in Europe, 8-9\% in Latin America, $2-4 \%$ in Canada (Repetti \& Jung, 2013). Therefore, the sector has attracted the interest of both marketers and policy makers, even though "...there is little agreement among researchers about the appropriate way to conceptualize and quantify the effects of gambling on society" (Walker, 2007, p. 609).

As for marketers, being part of the entertainment sector, gaming services are subject to a product life cycle: tastes and preferences of customers change and firms have to adapt or renovate their offer to keep on being competitive and "appealing". Thus, innovation and marketing are necessary to keep up with a market that constantly evolves and to avoid losing customers. This is even more true now that technological changes have introduced new ways of distributing gambling products (through digital online platforms) and new types of games. Together with the fall in trade barriers, this has increased the number of available substitutes and operators, opening national markets to foreign competition.

As for policy makers, traditionally, the disquiet towards the social costs of gambling activity, in particular the effects on excessive gamblers and the ease of criminal involvement, has explained the regulatory role of the state in the sector as a social guardian and a consumers' protector (for an analysis of these arguments in the literature, see, among others, Eadington, 2004; Smith, 2000; Taylor \& Kopp, 1991; Netemeyer et al., 1998). While proving more effective than prohibition in reducing illegal gambling, legalization and regulation have produced a base for taxation, introducing a fiscal stake of governments in the gambling industry (this ambiguity was pointed out at least since De Viti De Marco, 1936).

Online gambling has brought new arguments to the debate. The revolutionary technological and commercial development of the internet enabled operators to create new gambling platforms, virtual spaces in which customers can easily gamble online behind screens via a mouse click (Gariban et al., 2013). As expected, this market segment has undergone a rapid growth (Brindley, 1999), reaching a gross gaming win of $\$ 30$ billion and almost 3.000 internet sites in 2012 (Repetti \& Jung, 2013). Among the new problems introduced by remote gambling, there are the ease of access to 24 hour open virtual facilities, the potential for consumers' fraud (Miller, 2006), the strong participation of younger adults (Griffiths et al., 2010) and underage gambling. Moreover, 
online environments may exacerbate the risk of compulsive behavior, with the connected loss of money and time, since they influence mental processes driving spending decisions and gambling experiences (Siemens \& Kopp, 2011).

In this exploratory study, we analyze the different motivational aspects that characterize skill and luck games gamblers among college students, in order to derive elements useful in shaping both marketing and public policies in the new gambling environments.

\section{Literature Review}

\subsection{Motivations for Gambling}

Under an economic perspective, gambling consists in putting a given amount of money at stake, bearing the risk of losing it, but with the chance of winning a larger amount. Given that the amount of money staked by gamblers is lower than that distributed in winnings, the activity entails an expected loss. This feature has originated a cognitive-based explanation of gambling motivations based on the existence of a faulty reasoning: gamblers behave as if they could control the outcome of unpredictable events and/or think that an event is more predictable than it actually is (Ladouceur \& Walker, 1996; Miyazaki et al., 2001). Clotfelter \& Cook (1993) coined the term gambler's fallacy to denote the belief that the probability of a gambling event is lower once that event just occurred, even if the probability of its occurrence is independent across periods. Recently, the link between probability estimation and personality type has also been explored: Capra et al. (2013) find that "motivated" people, that is, people who are controlled and emotionally stable, consider gambling more attractive than impulsive people, since, though being risk averse, they positively focus on payoffs. However, winning money is not the only motive why people gamble: several studies have shown that people gamble also for excitement, challenge, socialization, escape (see, for instance, Walker, 1992; Browne \& Brown, 1994; Griffiths, 1995; Rogers, 1998; Aasved, 2003; Lam, 2007). Chantal et al. (2001) connect the motivational profile to the degree of gambling involvement. Besides these functional motives, also the personality traits antecedents of different gambling products have been studied by means of hierarchical models of motivations and personality (Fang \& Mowen, 2009). Factors others than money may represent a sort of reward, which may well exceed the expected loss from gambling. Under this perspective, regular gambling (not problem gambling) might look less irrational even if the expected monetary gain from it is negative: gambling is a leisure activity and, in order to undertake it, people are willing to spend money.

The literature has also pointed out the relevance of gender in determining gambling involvement. Men engage in gambling more than women do (Welte et al., 2002; Volberg, 2003). Also, men are more likely to engage in cards games and sports betting, while women are more likely to play with slots machines and promotional games (Fang \& Mowen, 2009); finally, motives such as excitement, challenge and escape are stronger in men than in women (McDaniel \& Zuckerman, 2003). Since gambling motivations differ across games, their understanding can help marketers in promoting gambling products and policy makers in detecting and contrasting gambling problems and reduce social costs. For instance, Lam (2007) finds that consumers were motivated by excitement, challenge and money for lottery and sport betting, by socialization for card room and bingo. Fang and Mowen (2009) find that slots gamblers have the motives of excitement and escape; sports bettors of money, challenge and social contact; card gamblers of money, excitement, social interaction and challenge.

While the literature has focused on the motivational aspects concerning single gambling product, in this study we test whether the same kind of analysis allows identifying two broader categories of gamblers: skill games gamblers and luck games gamblers. The defining characteristic is that the result is only connected to the occurrence of a random event for the former, while it may depend also on the gambler's abilities for the latter.

\subsection{The Gambling Migration to the Digital Channels}

The interest in the subject also stems from the recent evolution of the market. This appears to be pointing at a marked segmentation with respect to the nature of the games (skill or luck) and the distribution channel (online or offline). Luck games gamblers use traditional channels and skill games gamblers prefer the internet (Gandolfo $\&$ De Bonis, 2011), as summarized in Figure 1. 


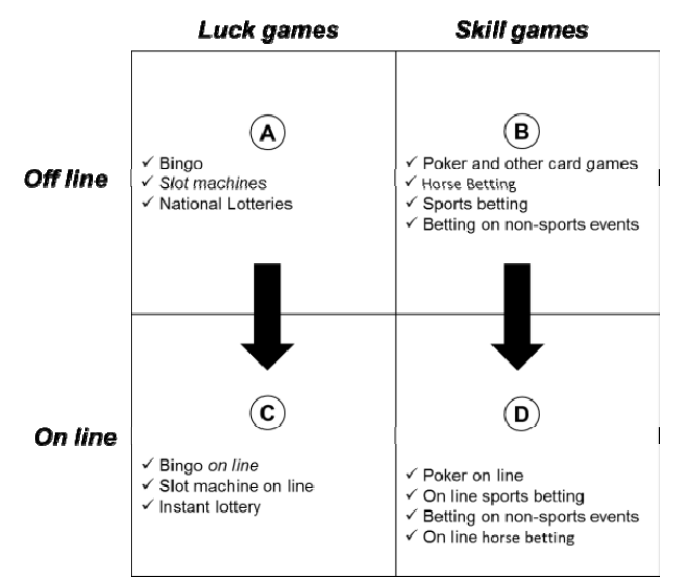

Figure 1. The segmentation of the gambling market and the "digital migration process"

Actually, the technological evolution in the supply of gambling products makes the traditional distinction between games "in the casino" and "out of the casino" obsolete. In fact, even though the data show that offline luck games (segment A) are still the leaders of the worldwide market, it is very likely that over the next years a drastic reshaping of the strength relationships between different market segments will take place. If, on the one hand, a decrease in the interest for traditional games has been recorded (in particular lotteries and games based on drawing numbers), on the other hand, we witness the success of skill games, and especially those played on the internet (segment D). These currently represent the most interesting market segment, both for gross gaming revenues and for the strategic developments that will take place in the European countries where online gaming is legal. In addition to this, a new type of products is expected to grow exponentially over the next years, that is, online luck games available on internet digital platforms (segment $\mathrm{C}$ ). Their spread will speed up the entrance in the maturity and decline phases of traditional luck games (segment A).

The objective of this exploratory study is thus to provide a better understanding of regular gambling (i.e., not problem gambling), in particular the motivational aspects of the behavior across two broad categories of games, skill and luck ones. Our hypothesis is that the skill games gambler's profile is characterized, in line with the existing results on cards games and sports betting, by a relevant social interaction motivation; connected to this, another element is the perception of a low risk of losing acquaintances' esteem because of gambling involvement. A further distinguishing aspect, related to the need of using skills when playing, is a controlled attitude, in opposition to impulsiveness; this element so far has only been considered as a determinant of the degree of involvement in gambling, not of the choice among types of games. The luck games gambler's profile, instead, is characterized by the money motive, impulsiveness and the perception of a high risk of losing family and friends esteem because of gambling.

\section{Method}

\subsection{Characteristics and Enrollment of the Participants}

The basis of our research is a self-reporting survey conducted among students of the University of Pisa (Italy). The choice of a sample composed by university students is due not only to the ease of contacting them as members of the same institution, but also to the relevance of the impact of gambling on youth. This is especially true for the current generation, that is the first one having been exposed to a largely liberalized environment and is known to exhibit a high diffusion of gambling (Williams et al., 2006); a further reason is given by the diffusion of the internet among younger people, also as a platform for gambling (Griffiths et al., 2010). In the period 31st July-17th October 2013, we administered an online questionnaire to all enrolled students who had taken at least one exam among the courses taught in the Department of Economics and Management. The link to the questionnaire was sent by e-mail to 8.942 students, obtaining 855 answers.

Figure 2 shows the dynamics of the students' participation in the survey along the 78 days in which they had access to the online questionnaire. The solid curve represents the number of questionnaires completed at 11.00 p.m. of each day, while the dashed curve shows the number of questionnaires the compilation of which was interrupted before ending. Only data from completed questionnaires were used in our analysis. It is possible to distinguish five phases in the dynamics of responses. The first phase is characterized by a consistent inflow of questionnaires ( 200 of them were completed in 7 days). The second phase, coinciding with academic vacations, 
is characterized by a moderate participation in the survey. The third and fourth phases were triggered by a reminder sent by e-mail to students (on the 11th and on the 16th of September 2013, respectively), followed by the ending phase (the survey was closed on October 16th). Overall, 1.069 questionnaires were registered on the server, of which 855 were completed ones and 476 had been interrupted before the end.

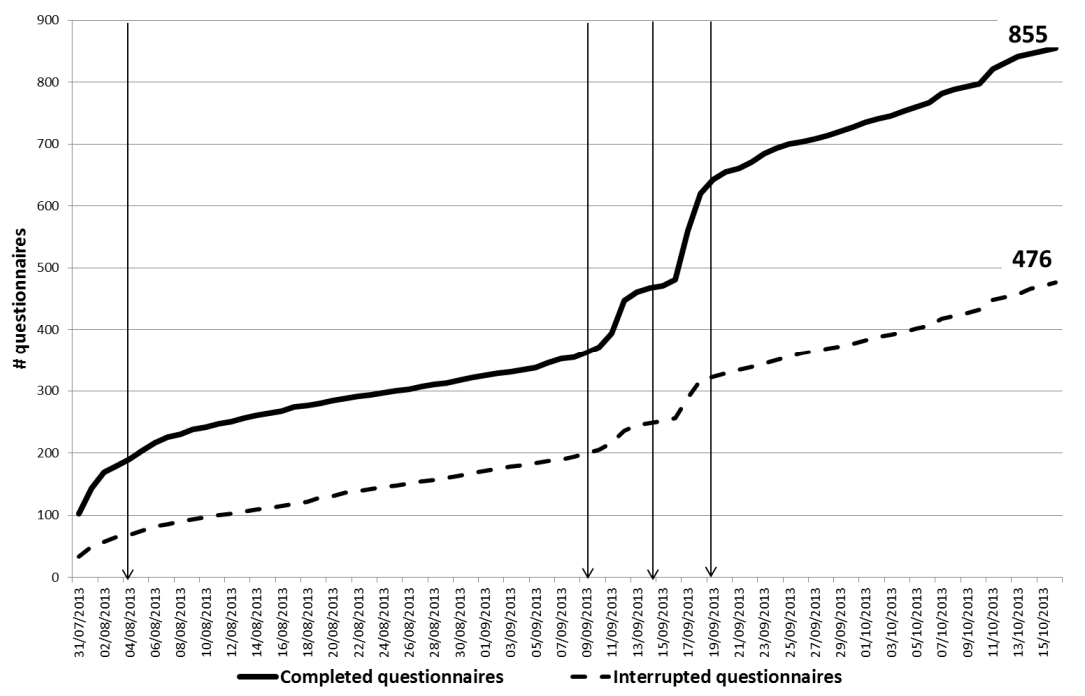

Figure 2. Dynamics of responses

The average age of respondents was 25.29 (s.d. 5.04); 57.63\% were women. Actual gamblers were $43.27 \%$ ( $24.21 \%$ were men, $18.95 \%$ women); among actual gamblers, $27.64 \%$ played exclusively skill games $(23.31 \%$ were men, $4.34 \%$ women), $36.59 \%$ exclusively luck games ( $9.76 \%$ men, $26.83 \%$ women); the rest played both types of games: $9.21 \%$ (men: $7.32 \%$, women $1.90 \%$ ) played skill games more than $50 \%$ of the times, while $4.61 \%$ played luck games more than $50 \%$ of the times (men: $3.25 \%$, women: $1.76 \%$ ); $4.07 \%$ (men: $2.98 \%$, women $1.08 \%)$ played both types of games with the same frequency. Finally, $17.89 \%(9.49 \%$ men, $8.40 \%$ women) did not answer the relevant question.

The questionnaire was divided into eight sections, each of them concerning a particular aspect (attitudes towards gambling, motives for gambling, perceived risks, types of games played, amount of money spent, gambling frequency, socio-demographic variables, attitudes towards risk); filter questions allowed to delineate specific paths for each respondent's profile (gambler, not gambler, online gambler, etc.).

In what follows, we only consider those sections on which we constructed the variables relevant to our analysis. As recalled above, different motivations for different gambling products have been found in the literature. In our survey, respondents were asked to measure the strength of eight motives along a $0-10$ scale.

\section{Results}

Table 1 summarizes the results ("Skill" comprises exclusively and prevalently skill games gamblers, "Luck" exclusively and prevalently luck games gamblers).

The main result is that winning money is the strongest motive for both types of gamblers, but if it is undoubtedly "the" motive for luck games gamblers, for skill games ones other motives are also relevant: excitement, social interaction, challenge. It should also be added that challenge, escape and excitement are highly linked to gender, average values being consistently higher for men than for women across all game types. 
Table 1. Motives for gambling: average score (min-max-s.d.)

\begin{tabular}{|c|c|c|c|c|c|c|c|}
\hline \multicolumn{2}{|c|}{ Motive } & \multicolumn{3}{|l|}{ Skill } & \multicolumn{3}{|l|}{ Luck } \\
\hline & & $\begin{array}{l}\text { Average } \\
\text { score }\end{array}$ & Min-max & $\begin{array}{l}\text { Standard } \\
\text { deviation }\end{array}$ & $\begin{array}{l}\text { Average } \\
\text { score }\end{array}$ & Min-max & $\begin{array}{l}\text { Standard } \\
\text { deviation }\end{array}$ \\
\hline 1. & Challenge & 2.46 & $0.30-9.66$ & 2.53 & 0.94 & $0.00-7.96$ & 1.55 \\
\hline 2. & Escape from boredom & 1.76 & $0.00-9.14$ & 1.96 & 1.1 & $0.01-8.72$ & 1.58 \\
\hline 3. & Money & 4.33 & $0.02-9.81$ & 2.79 & 5.90 & $0.00-9.92$ & 2.81 \\
\hline 4. & Excitement & 3.34 & $0.04-9.18$ & 2.31 & 1.84 & $0.01-9.47$ & 2.04 \\
\hline 5. & Escape from sadness and depression & 1.19 & $0.02-9.40$ & 1.66 & 0.87 & $1.32-7.96$ & 1.32 \\
\hline 6. & Socialization & 3.08 & $0.06-9.75$ & 2.56 & 1.25 & $0.01-9.67$ & 1.87 \\
\hline 7. & Relax & 1.65 & $0.02-8.60$ & 2.01 & 1.0 & $0.00-7.45$ & 1.53 \\
\hline 8. & Entertainment & 3,00 & $0.05-9.77$ & 2.59 & 2.38 & $0.00-9.74$ & 2.51 \\
\hline 9. & Other reasons & -- & -- & -- & -- & -- & -- \\
\hline \multicolumn{2}{|c|}{ Number of respondents } & 136 & & & 152 & & \\
\hline
\end{tabular}

In addition to motives for gambling, we also consider the motivations for initially starting participation in gambling activities. Though having received attention for their implications in generating problem gamblers (Tseet al., 2005), these aspects have not been considered much as for regular gambling. We think, instead, that the initial motive may represent an important element for both marketers and policy makers, as it will be argued in the last section. We asked respondents to evaluate the strength of the following motives: 1 . Presence of a gambler in the family; 2. Friends who already gambled; 3. Invitation to participate to group bets; 4 . Excitement; 5. Winning money; 6. Curiosity about the game; 7. Popularity of the game; 8. Commercials promoting the game.

9. Challenge. Table 2 summarizes the results.

Table 2. Motives for starting gambling activity: average score (min-max-s.d.)

\begin{tabular}{|c|c|c|c|c|c|c|c|}
\hline \multicolumn{2}{|c|}{ Initial motive } & \multicolumn{3}{|l|}{ Skill } & \multicolumn{3}{|l|}{ Luck } \\
\hline & & $\begin{array}{l}\text { Average } \\
\text { score }\end{array}$ & Min-max & $\begin{array}{l}\text { Standard } \\
\text { deviation }\end{array}$ & $\begin{array}{l}\text { Average } \\
\text { score }\end{array}$ & Min-max & $\begin{array}{l}\text { Standard } \\
\text { deviation }\end{array}$ \\
\hline 1. & Family & 1.44 & $0.00-9.21$ & 1.89 & 1.15 & $0.01-9.70$ & 1.82 \\
\hline 2. & Friends & 2.04 & $0.00-9.88$ & 2.24 & 3.66 & $0.07-9.90$ & 2.32 \\
\hline 3. & Invitation to group betting & 0.91 & $0.00-9.35$ & 1.46 & 1.71 & $0.02-9.89$ & 2.12 \\
\hline 4. & Excitement & 1.96 & $0.03-9.30$ & 2.22 & 2.48 & $0.03-7.70$ & 1.91 \\
\hline 5. & Money & 5.00 & $0.09-9.90$ & 2.58 & 3.85 & $0.03-9.90$ & 2.60 \\
\hline 6. & Curiosity & 2.22 & $0.00-9.88$ & 2.10 & 2.84 & $0.05-8.79$ & 2.31 \\
\hline 7. & Popularity of the game & 2.27 & $0.01-9.80$ & 2.16 & 2.03 & $0.01-8.93$ & 2.16 \\
\hline 8. & Advertising & 1.63 & $0.01-9.92$ & 2.04 & 1.06 & $0.01-8.44$ & 1.56 \\
\hline 9. & Challenge & 0.89 & $0.00-8.89$ & 1.49 & 2.46 & $0.02-9.68$ & 2.59 \\
\hline 10. & Other motives & -- & -- & -- & -- & -- & -- \\
\hline \multicolumn{2}{|c|}{ Number of respondents } & 136 & & & 152 & & \\
\hline
\end{tabular}

Money is again the most important motivation. A comparison between Table 1 and Table 2 shows a different evolution of the strength of this motive as for skill and luck games gamblers: its relevance increases through time for the former group, while it decreases for the latter one. As for the social interaction motive, it should be noted that it is almost as strong as the money one for skill games gamblers and that it does not decrease with time; this is in contrast with the case of luck games gamblers, for whom social contact significantly decreases.

The result for challenge is much similar to that of Table 1 . Table 2 also shows how peer influence is stronger than parental one in influencing initial gamblers. The significance of the money and social interactions motives in marking the difference between the skill games gambler profile and the luck games gambler profile will be tested below.

In order to better understand and differentiate the motivational aspects of skill and luck games gamblers, we have also investigated the entertaining content of the two different forms of games, i.e. the type of amusement being derived by playing them.

To do this, we have asked which moment respondents considered the most exciting one in the process of 
gambling. The most frequent answers were "when waiting to know the results" and "when imagining what to do with the amount won", the second one having been indicated by the absolute majority of women playing luck games. "When challenging other gamblers" resulted to be an important reason of amusement for male skill games gamblers.

The main difference between luck and skill games gamblers, irrespectively of the gender, was the relevance for the latter of the moment "when the game strategies are chosen". Besides confirming the importance of motives other than money for skill games gamblers, we believe that this aspect helps defining the skill games gambler type, especially once it is associated to another characteristic, that is, the planning attitude when gambling. In fact, respondents were asked to mark, on a 0-10 scale, by how much their decisions of playing were well planned (with 0 corresponding to an impulsive decision). The average (max-min-s.d.) value was 3.21 (9.97-0-3.4), which increased to 5.2 (9.97-0.64-3.43) for respondents playing exclusively skill games - 4.89 (9.97-0.04-3.43) for those playing prevalently skill-, while falling to $2.62(9.69-0-2.6)$ for those playing exclusively luck games-2.8 (9.69-0-2.8) for those playing prevalently luck. In our opinion, this factor is a relevant one in explaining the choice between skill and luck games (rather than the more generic "excitement" motive).

Finally, we expect that people who perceive that involvement in gambling activities is associated to some sort of social stigma would not engage in games characterized by strong motivation for social interaction. In order to test this hypothesis, respondents were asked to evaluate, on a 0-10 scale, the risk of losing family/friends esteem. The average result was a value of 4.48 (9.9-0-2.96) for those playing prevalently skill games and of 4.25 (9.9-0.02-2.89) for those playing exclusively skill games, while people playing prevalently or only luck games consider this risk to be higher, with average scores of $5.76(10-0.05-2.91)$ and 5.81 (10-0.05-2.99), respectively.

\subsection{Regression Analysis}

To test the significance of gambling motivations and other factors in explaining the choice between skill and luck games, we apply regression analysis to the data obtained from the survey. Our dependent variable is being a skill games gambler or not (that is, a luck games gamblers). It is, therefore, an indicator variable, which reflects a qualitative rather than a quantitative description of the data; to be included in the regression, it must be represented numerically, which is achieved by defining a variable $S$, that takes the value 1 in the case of a skill games gambler, 0 in the case of a luck games one. In particular, $\mathrm{S}$ is equal to 1 if the respondent played skill games exclusively or more than $50 \%$ of the time, while it is equal to 0 if the respondent played luck games exclusively or more than $50 \%$ of the times (other profiles being excluded from the sample). The explanatory variables are a constant, the money motive, the social interaction motive, the risk of losing social esteem, the planning attitude, gender and age.

As for gender, our hypothesis is that it represents a predictor of the choice of the game type, in that it summarizes traits and motives that specifically characterize men with respect to women (among which, competitiveness, challenge, excitement, escape). The higher propensity to gamble that characterizes men with respect to women, already pointed at in the literature (Volberg, 2003; McDaniel \& Zuckerman, 2003; Welte et al., 2002), can in part be explained by the different strength of these factors.

Age is also a variable with an explanatory power tested in the literature (Fang \&Mowen, 2009; Lam, 2007), even if mainly in samples containing both young people and adults. Though our sample concerns university students, we think it might be a relevant explanatory variable because of the age dispersion of the sample and because of the already mentioned correlation between skill games and the internet: many skill games have lately been introduced on the online platform and possibly younger students have more easily got in touch with them. Given the focus on university students, we do not use other demographic variables, like instruction level and income (for an analysis of the influence of these and other demographic variables on gambling behavior see, for instance, Herring \& Bledsoe, 1994; Abbot \& Cramer, 1993; Brown et al., 1992).

With the exception of gender, all explanatory variables are quantitative ones, the value being given by the score attributed to it by the respondent on a 0-10 scale, as explained above; age is number of years. Gender is a qualitative variable, which takes the value 0 if the respondent is a woman and 1 if he is a man. Being a woman is a benchmark, the coefficient of the variable gender estimating the impact of being a man rather than a woman on the probability of being a skill games gambler.

Given the discrete nature of the dependent variable, we use a probit model (the results with a logistic regression are, as one would expect, very similar, apart from a scale factor); coefficients estimate the impact of the relevant variable on the probability of being a skill games gambler. Results are summarized in Table 3. Table 4 summarizes the results for the subsample of those playing exclusively either skill or luck games. 
Table 3. Regression coefficients for motivators and demographics of gambling behaviour (exclusively or prevalently skill games gamblers)

\begin{tabular}{|c|c|c|c|c|}
\hline & Coefficient & Std. Error & t-value & t-prob \\
\hline Constant & 1.85618 & 0.6132 & 3.03 & 0.003 \\
\hline Age & -0.0857544 & 0.02113 & -4.06 & 0.000 \\
\hline Money & -0.216586 & 0.03995 & -5.42 & 0.000 \\
\hline Social factor & 0.218776 & 0.06465 & 4.74 & 0.000 \\
\hline Loss of social esteem & -0.0889042 & 0.03521 & -2.53 & 0.012 \\
\hline Planning attitude & 0.135103 & 0.03171 & 4.26 & 0.000 \\
\hline Gender & 1.50620 & 0.2309 & 6.52 & 0.000 \\
\hline Log-likelihood: & \multicolumn{4}{|l|}{-97.9190462} \\
\hline No. of states: & \multicolumn{4}{|l|}{2} \\
\hline No. of observations : & \multicolumn{4}{|l|}{280} \\
\hline No. of parameters: & \multicolumn{4}{|l|}{7} \\
\hline Baseline log-likelihood: & \multicolumn{4}{|l|}{-194.0812} \\
\hline Test $\operatorname{Chi}^{2}(6)$ : & \multicolumn{4}{|c|}{$192.32[0.0000]^{* *}$} \\
\hline AIC: & \multicolumn{4}{|c|}{209.838092} \\
\hline AIC/n: & \multicolumn{4}{|l|}{0.749421759} \\
\hline Mean (S): & \multicolumn{4}{|l|}{0.467857} \\
\hline $\operatorname{Var}(\mathrm{S}):$ & \multicolumn{4}{|c|}{0.248967} \\
\hline \multirow[t]{2}{*}{ Newton estimation (eps $1=0.0001$; eps $2=0.005)$ : } & \multicolumn{4}{|c|}{ Strong convergence } \\
\hline & Count & Frequency & Probability & $\operatorname{loglik}$ \\
\hline State 0 & 149 & 0.53214 & 0.53122 & -48.13 \\
\hline State 1 & 131 & 0.46786 & 0.46878 & -49.79 \\
\hline Total & 280 & 1.00000 & 1.00000 & -97.92 \\
\hline
\end{tabular}

Table 4. Regression coefficients for motivators and demographics of gambling behaviour (exclusively or prevalently skill games gamblers)

\begin{tabular}{lllll}
\hline & Coefficient & Std. Error & t-value & t-prob \\
\cline { 2 - 5 } Constant & 1.74590 & 0.6915 & 2.53 & 0.012 \\
Gender & 1.68770 & 0.2882 & 5.86 & 0.000 \\
Age & -0.0884505 & 0.02398 & -3.69 & 0.000 \\
Money & -0.217762 & 0.04775 & -4.56 & 0.000 \\
Social factor & 0.306692 & 0.06465 & 4.74 & 0.000 \\
Loss of social esteem & -0.135693 & 0.04387 & -3.09 & 0.002 \\
Planning attitude & 0.158549 & 0.03943 & 4.02 & 0.000 \\
\hline Log-likelihood: & -64.182963 & & \\
No. of states: & 2 & & & \\
No. of observations : & 230 & & \\
No. of parameters: & 7 & & & \\
Baseline log-likelihood: & -159.4239 & & \\
Test Chi2( 6): & $190.48[0.0000]^{* *}$ & & & \\
AIC: & 142.365926 & & & \\
AIC/n: & 0.618982287 & & & -33.45 \\
Mean (S): & 0.426087 & & & -64.18 \\
Var (S): & 0.244537 & & & \\
Newton estimation (eps1=0.0001; eps2=0.005): & Strong convergence & & & \\
\hline & Count & Frequency & Probability & loglik \\
State 0 & 132 & 0.57391 & 0.57257 \\
State 1 & 98 & 0.42609 & 0.42743 \\
Total & 230 & 1.00000 & 1.00000 \\
\hline
\end{tabular}

As the results show, the respondents' gambling motivations vary significantly across the two forms of gambling products, in a way that is consistent with the analysis of the previous sections. All explanatory variables are highly significant. To summarize: 
- the probability of choosing skill games is positively correlated to being a male and to the socialization motive, while the probability of playing luck games increases with the strength of the money motive;

- in addition, the risk of losing social esteem is inversely related to the probability of playing skill games, which, as argued above, can be connected to the social interaction motive;

- the planning attitude is positively correlated to the probability of playing skill games;

- the negative effect of age on the probability of playing skill games might derive from the recent diffusion of online skill games. One can compare this result with the findings by Herring \& Bledsoe (1994), Brown et al.(1992), and Aasved (2003), showing that older people are more likely to buy lotteries than younger people are.

\section{Discussion}

\subsection{General Implications}

The different characteristics of skill and luck gamblers illustrated in the previous sections call for different promotion strategies on part of marketers. As for skill games, the aspects on which commercial messages should focus on are, besides money, challenge and social interaction, already indicated for some skill games in the literature (Lam, 2007; Fang \& Mowen, 2009). Our analysis also shows that the allure of a game consisting in elaborating a strategy aimed at victory in a sport-like competition could be an effective way to characterize advertising.

In the case of luck games, instead, the possibility of winning money should be the predominant aspect, together with the attraction exerted by what one could do with it. However, the design of commercial strategies should take into account the problem of excessive gambling, which also represents the main justification for public intervention in the sector. In particular, it is widely recognized that the challenge and money motives are among the roots of problem gambling, the former being the most important motive for luck games gamblers, both being relevant for skill games gamblers. Socialization is considered a double-edged motive: it can act as a safeguard against excessive gambling, but it can also be the way to be led into gambling, because of family or peer induction.

To evaluate these aspects in the two forms of games being analyzed, one should also consider how motivational aspects change through time. In terms of our analysis, this implies considering how the relevance of motives changes between the phase of being introduced into gambling and the phase in which gambling behavior is consolidated.

For gamblers playing luck games, we found, as illustrated above, that the strength of the money motive increases, which confirms the connected risk of degenerating into problem gambling once you are inside the activity. For skill games gamblers, both the money and sociality motives decrease in strength, while the challenge motive remains unaltered, so that the risk of problem gambling does not look less relevant for them with respect to luck games gamblers.

These results call for a cooperation between companies providing gaming services and regulators to fight the risk of problem gambling. First, the possibility of winning large amounts of money should not be exaggerated in commercial messages, for both types of games. As for skill games, the role of the socialization motive could be used to find ways to involve friends and family members in tackling excessive gambling problems, once detected. However, when shaping the intervention for skill games gamblers, one should consider another factor that emerges from our analysis, that is, the extensive use of the internet when playing.

\subsection{Implications for Online Gambling}

The current success of gambling products distributed through digital channels is justified by their ability to meet the expectations and tastes of a relevant component of demand that traditional channels are not able to satisfy, namely, that of consumers who are younger and more familiar with digital technologies.

With respect to this, a more individualistic gambling behavior is establishing itself. People gamble in front of the PC or the television, often alone; they play in a decontextualized way, as the access to online platforms is possible at whatever time and place, if an internet connection is available; and in a globalized way, since gamblers can connect from all over the world. It is evident that this type of supply makes access to gambling behavior much easier, especially for the younger customers, with relevant social implications for the risk of increased pathologic behavior, in particular among teenagers.

In addition to this, the migration towards digital gambling causes evident effects on the supply side. Digital gambling, in fact, contributes to extending the range of available products and encourages the entrance on the national market of new comers, who focus on the online segment. Moreover, it drives several multi-product 
suppliers in the offline market to equip themselves to supply also online products, thus becoming multi-channel operators.

One of the results of our survey is the strong correlation between game type (skill or luck) and gambling environment (online or traditional). As shown in Table 5, while luck games gamblers use the traditional channels, skill games gamblers prefer the internet. When considering policies directed to the latter, therefore, the implications of online playing cannot be overlooked.

Table5. Gambling environment and type of game (skill or luck)

\begin{tabular}{llll}
\hline Environment/Game type & Prevalently and exclusively online & Mixed & Prevalently and exclusively traditional \\
\hline $\begin{array}{l}\text { Prevalently and exclusively } \\
\text { skill }\end{array}$ & $94,8 \%$ & --- & $5,2 \%$ \\
\hline Mixed & --- & $100 \%$ & --- \\
\hline $\begin{array}{l}\text { Prevalently and exclusively } \\
\text { luck }\end{array}$ & --- & --- & $100 \%$ \\
\hline
\end{tabular}

A first observation concerns the role of the socialization aspect in the case of skill gamblers. In fact, for internet gamblers, social interaction does not take the form of physically playing together as in traditional cards or bingo rooms: in our sample, less than $7 \%$ of online gamblers usually plays together with other people around. Thus, the positive role of sociality as a safeguard against problem gambling appears jeopardized by its 'virtual' character. On the contrary, the negative effect of being introduced into gambling by friends appears very relevant, since this is the case for about $50 \%$ of internet gamblers. Thus, once the peculiarity of their playing online is taken into account, for skill games excessive gambling might represent a risk much higher than expected. Besides this, one should also consider the problems deriving from the online environment itself, referred to in the introductory section. Our survey confirms the perception of operating in a risky environment pointed at in the literature.

The risk connected to having an all day long open virtual facility is confirmed by the fact that the most highly scored motives for preferring online are the possibility of playing at home and whenever one likes it, with 6.29 (9.87-0.6-2.43)and 6.26 (9.83-0.6-2.63) average score (max-min-s.d.) on a 0-10 scale, respectively.

In addition, the risks of losing the sense of money and time being spent, and of being victims of illegal control, are all scored more than 5.0 on average. The loss of control of "virtual" money being spent can be a reason for cooperation between gaming companies and regulators to enhance systems that allow self-exclusion and betting limits for consumers, or even systems slowing-down or even briefly stopping betting activity, once it exceeds given limits (Siemens \& Kopp, 2011).

Those not using the internet have similar, although stronger, fears; differently from online gamblers, however, the most risky aspect is financial fraud, which obtained an average score of 6.44 (9.93-0.02-3.25) beside the score 4.78 (9.7-0.08-2.6) given by online gamblers. This fear might explain the preference of online gamblers for domestic providers ( $75 \%$ of our sample only played on Italian sites). It thus appears that a strict control on gambling performed by the player's jurisdiction represents a way to enhance reputation for providers. Even if it might increase the number of online gamblers, it would also allow regulators to better intervene to protect consumers. Internet gambling is a young market that rapidly expanded during the first decade of the twenty-first century (Williams et al., 2012). Since the first online casinos were launched in 1995, a rapid expansion of the internet gambling industry has taken place.

The future of the gaming sector seems, therefore, characterized by important challenges that private operators and policy makers have to face to ensure a regular and socially responsible development of this important component of the national economy of many countries.

\section{References}

Aasved, M. (2003). The Sociology of Gambling. Springfield: Charles C. Thomas.

Abbot, D. A., \& Cramer, S. L. (1993). Gambling Attitudes and Participation: A Midwestern Study. Journal of Gambling Studies, 9(3), 247-263. http://dx.doi.org/10.1007/BF01015921

Brindley, C. (1999). The Marketing of Gambling on the Internet. Internet Research: Electronic Networking Applications and Policy, 9(4), 281-286. http://dx.doi.org/10.1108/10662249910286798

Brown, D. J., Kaldenberg, D. O., \& Browne B. A. (1992). Socioeconomic Status and Playing the Lotteries. Sociology and Social Research, 76, 161-167. 
Browne, B. A., \& Brown D. J. (1994). Predictors of Lottery Gambling Among American College Students. Journal of Social Psychology, 134(3), 339-347. http://dx.doi.org/10.1080/00224545.1994.9711738

Capra, C. M., Jiang, B., Engelmann, J. B., \& Berns, G. S. (2013). Can Personality Type Explain Heterogeneity in Probability Distortions? Journal of Neuroscience, Psychology, and Economics, 6(3), 151-166. http://dx.doi.org/10.1037/a0033708

Clotfelter, C. T., \& Cook, P. J. (1993). The 'Gambler's Fallacy' in Lottery Play. Management Science, 39(12), 1521-1525. http://dx.doi.org/10.1287/mnsc.39.12.1521

De Viti De Marco, A. (1936). First Principles of Public Finance. London: Jonathan Cape.

Eadington, W. R. (2004). The Future of Online Gambling in the United States and Elsewhere. Journal of Public Policy \& Marketing, 23(Fall), 214-219. http://dx.doi.org/10.1509/jppm.23.2.214.51399

Fang, X., \& Mowen, J. C. (2009). Examining the Trait and Functional Motive Antecedents of Four Gambling Activities: Slot Machines, Skilled Card Games, Sports Betting, and Promotional Games. Journal of Consumer Marketing, 26(2), 121-131. http://dx.doi.org/10.1108/07363760910940483

Gandolfo, A., \& De Bonis, V. (2011). Evoluzione e innovazione del gioco pubblico in Italia: analisi esplorativa di un mercato in rapido cambiamento. Finanza, Marketing e Produzione, 3, 105-137. Milano: EGEA.

Gariban, G., Kingma, S. F., \& Zhorowska, N. (2014). Never a dull day. Exploring the material organization of virtual gambling. In R. Cassidy et al. (Eds.), Qualitative Research in Gambling. Exploring the production and consumption of risk (pp. 107-121). London: Routledge.

Griffiths, M., Parke J., \& Wood, R. (2010). Online Poker Gambling in University Students: Further Findings from an Online Survey. International Journal of Mental Health and Addiction, 8, 82-89. $\mathrm{http}: / / \mathrm{dx}$. doi.org/10.1007/s11469-009-9203-7

Grifiths, M. (1995). Adolescent Gambling. London: Routledge.

Herring, M., \& Bledsoe, T. (1994). A Model of Lottery Participation: Demographics, Context, and Attitudes. Policy Studies Journal, 22(2), 245-257. http://dx.doi.org/10.1111/j.1541-0072.1994.tb01466.x

Humphreys, A. (2010). Megamarketing: The Creation of Markets as a Social Process. Journal of Marketing, 74, 1-19. http://dx.doi.org/10.1509/jmkg.74.2.1

Humphreys, A. (2010). Semiotic Structure and the Legitimation of Consumption Practices: The Case of Casino Gambling. Journal of Consumer Research, 37(October), 490-510.

Ladouceur, R., \& Walker, M. (1996). A Cognitive Perspective on Gambling. In Paul Salkovskis (Ed.), Trends in Cognitive and Behavioral Therapies (pp. 89-120). New York: John Wiley and Sons.

Lam, D. (2007). An Exploratory Study of Gambling Motivations and Their Impact on the Purchase Frequencies of Various Gambling Products. Psychology and Marketing, 24(9), 815-827. http://dx.doi.org/10.1002/mar.20185

McDaniel, S. R., \& Zuckerman M. (2003). The Relationship of Impulsive Sensation Seeking and Gender to Interest and Participation. Gambling Activities, Personality and Individual Differences, 35(6), 1385-1400. http://dx.doi.org/10.1016/S0191-8869(02)00357-4 (02)00357-4

Miller, R. (2006). The Need for Self-Regulation and Alternative Dispute Resolution to Moderate Consumer Perceptions of Perceived Risk with Internet Gambling. UNLV Gaming Research \& Review Journal, 10(1), 51-58.

Miyazaki, A. D., Brumbaugh, A. M., \& Sprott, D. E. (2001). Promoting and Countering Consumer Misconception of Random Events: The Case of Perceived Control and State-Sponsored Lotteries. Journal of Public Policy and Marketing, 20(2), 254-267. http://dx.doi.org/10.1509/jppm.20.2.254.17364

Netemeyer, R. G., Burton, S., Cole, L. K., Williamson, D. A., Zucker, N., Bertman, L., \& Diefenbach, G. (1998). Characteristics and Beliefs Associated with Probable Pathological Gambling: A Pilot Study with Implications for the National Gambling Impact and Policy Commission. Journal of Public Policy and Marketing, 17(2), 147-160.

Repetti, T., \& Jung, S. Y. (2013). Building the First Gaming Master's Program: An Industry Perspective. UNLV Gaming Research \& Review Journal, 17(2), 63-79.

Rogers, P. (1998). The Cognitive Psychology of Lottery Gambling: A Theoretical Review. Journal of Gambling Studies, 14(2), 111-134. http://dx.doi.org/10.1023/A:1023042708217 
Siemens, J. C., \& Kopp, S. W. (2011). The Influence of Online Gambling Environments on Self-Control. Journal of Public Policy \& Marketing, 30(2), 279-293. http://dx.doi.org/10.1509/jppm.30.2.279

Smith, J. (2000). Gambling Taxation: Public Equity in the Gambling Business. Australian Economic Review, 33(2), 120-144. http://dx.doi.org/10.1111/1467-8462.00143

Taylor, C. R., \& Kopp, S. W. (1992). Games Contests, and Sweepstakes Run Afoul: A State of Legal Disorder. Journal of Public Policy \& Marketing, 10(Spring), 199-213.

Tse, S., Abbott, M., Clarke, D., Townsend, S., Kingi, P., \& Manaia, W. (2005). Examining the Determinants of Problem Gambling, Health Research Council of New Zealand. Auckland UniServices Limited, University of Auckland.

Volberg, R. A. (2003). Has There Been a 'Feminization' of Gambling and Problem Gambling in the United States? The Electronic Journal of Gambling Issues, 8.

Walker, D. M. (2007). Problems in Quantifying the Social Costs and Benefits of Gambling. American Journal of Economics and Sociology, 66(3), 609-645. http://dx.doi.org/10.1111/j.1536-7150.2007.00529.x

Walker, M. B. (1992). The Psychology of Gambling. Oxford: Pergamon Press.

Watson, S., Liddell, P. Jr., Moore, R. S., \& Eshee, W. D. Jr. (2004). The Legalization of Internet Gambling: A Consumer Protection Perspective. Journal of Public Policy \& Marketing, 23(Fall), 209-213. http://dx.doi.org/10.1509/jppm.23.2.209.51401

Welte, J. W., Barnes, G. M., Wieczorek, W. F., Tidewell, M. C., \& Parker, J. (2002). Gambling Participation in the U.S.-Results from a National Survey. Journal of Gambling Studies, 18(4), 313-337. http://dx.doi.org/10.1023/A:1021019915591

Williams, R. J., Connolly, D., Wood, R. T., \&Nowatzki, N. (2006). Gambling and Problem Gambling in a Sample of University Students. Journal of Gambling Issues, 16(April), 1-14. http://dx.doi.org/10.4309/jgi.2006.16.19

Williams, R. J., Wood, R. T., \& Parke, J. (2012). The International Handbook of Internet Gambling. London: Routledge.

\section{Copyrights}

Copyright for this article is retained by the author(s), with first publication rights granted to the journal.

This is an open-access article distributed under the terms and conditions of the Creative Commons Attribution license (http://creativecommons.org/licenses/by/3.0/). 